\title{
Transplante uterino como alternativa terapêutica para infertilidade de fator uterino: uma revisão sistemática
}

\author{
Uterine transplantation as a therapeutic alternative for uterine factor infertility: a systematic \\ review
}

Trasplante uterino como alternativa terapéutica para la infertilidad por factor uterino: una revisión sistemática

Camila Azalim de Campos ${ }^{2 *}$, Aylandra Lara Silva Melo, Déborah Schulthais Ramos ${ }^{2}$, Gabriela Santos Perez ${ }^{2}$, Hérica Maris Martins Silva ${ }^{2}$, Izabela Vieira Duarte Baptista ${ }^{3}$, Izabella Moreira Fulgêncio ${ }^{2}$, Juliana de Souza Zerbini², Phillipe Augusto Marques Silva², Victor Eliel Bastos de Carvalho².

\section{RESUMO}

Objetivo: Descrever através de uma revisão sistemática a respeito do transplante uterino (TU), como opção terapêutica para mulheres com infertilidade absoluta do fator uterino (IAFU) com desejo reprodutivo. Métodos: A busca bibliográfica ocorreu nas bases de dados PubMed, LILACS e CAPES utilizando os descritores "infertility", "transplant" e "uterus", combinados entre si, assim como as palavras correspondentes em português e espanhol. Foram selecionados 5 ensaios clínicos. Resultados: A cirurgia para TU é recente e os estudos acerca dessa temática abordam diferentes aspectos relacionados ao procedimento, como a qualidade dos vasos sanguíneos da doadora, patologias vasculares uterinas e as diferenças entre as doadoras vivas e não vivas. Os critérios de seleção de doadoras também variam de acordo com cada ensaio clínico, sendo que a idade é considerada um fator de exclusão pela maioria. Foram considerados resultados positivos a presença de úteros viáveis com menstruação e/ou gestação com filho vivo. Considerações finais: O TU uterino se mostrou como uma opção terapêutica às mulheres com IAFU que desejam vivenciar as etapas da gestação, apesar de ser uma prática empírica, necessitando de maiores avanços nessa área, os estudos demonstraram bons resultados nos procedimentos já realizados.

Palavras-chave: Infertilidade, Útero, Transplante.

\section{ABSTRACT}

Objective: Describe through a systematic review regarding uterine transplantation (UT), as a therapeutic option for women with absolute uterine factor infertility (AUFI) who wish to get pregnant. Methods: The bibliographic search occurred in the PubMed, LILACS and CAPES databases using the descriptors "infertility", "transplant" and "uterus", combined with each other, as well as the corresponding words in Portuguese and Spanish. Five clinical trials were selected. Results: Surgery for UT is recent and studies on this topic address different criteria related to transplantation, such as the quality of donor blood vessels, uterine vascular pathologies and the differences between living and non-living donors. Donor selection criteria also vary according to each clinical trial, with age being considered an exclusion factor by the majority. The presence of viable uteri with menstruation and / or pregnancy with a live child were considered positive results. Final considerations: Uterine UT proved to be a therapeutic option for women with AUFI who wish to experience the stages of management, despite being an empirical practice, requiring further progress in this area, studies have shown good results transplants performed.

Keywords: Infertility, Uterus, Transplantation.

${ }^{1}$ Pontifícia Universidade Católica de Minas Gerais (PUC-MG), Contagem - MG.

*E-mail: azalimcamila@gmail.com

2Pontifícia Universidade Católica de Minas Gerais (PUC-MG), Betim - MG.

${ }^{3}$ Universidade Federal de Ouro Preto (UFOP), Ouro Preto - MG.

SUBMETIDO EM: 7/2020

ACEITO EM: 8/2020

PUBLICADO EM: 10/2020

REAS/EJCH | Vol.12(10) | e4626 | DOI: https://doi.org/10.25248/reas.e4626.2020

Página 1 de 9 


\section{RESUMEN}

Objetivo: Describir mediante una revisión sistemática sobre el trasplante uterino (TU), como una opción terapéutica para las mujeres con infertilidad absoluta por factor uterino (IAFU) que desean quedar embarazadas. Métodos: La búsqueda bibliográfica se realizó en las bases de datos PubMed, LILACS y CAPES utilizando los descriptores "infertilidad", "trasplante" y "útero", combinados entre sí. Se seleccionaron 5 ensayos clínicos. Resultados: La cirugía para la TU es reciente y los estudios sobre este tema abordan diferentes criterios relacionados con el trasplante, como la calidad de los vasos sanguineos de los donantes, las patologías vasculares uterinas y las diferencias entre los donantes vivos y los no vivos. Los criterios de selección de donantes también varían de acuerdo con cada ensayo clínico, y la mayoría considera la edad como factor de exclusión. La presencia de útero viable con la menstruación y / o el embarazo con un niño vivo se consideraron resultados positivos. Consideraciones finales: La TU uterina demostró ser una opción terapéutica para las mujeres con IAUF que desean experimentar las etapas de manejo, a pesar de ser una práctica empírica, que requiere un mayor progreso en esta área, los estudios han mostrado buenos resultados trasplantes realizados.

Palabras Clave: Infertilidad, Útero, Trasplante.

\section{INTRODUÇÃO}

A prevalência de infertilidade absoluta do fator uterino (IAFU) é de 1 a cada 500 mulheres em idade reprodutiva no mundo (O'DONOVAN L, et al., 2019; BRUNO B e ARORA KS, 2018). A IAFU pode ser conceituada como a ausência completa do útero ou a presença de um útero anatômico e fisiologicamente disfuncional (JONES BP, et al., 2019).

As causas desse tipo de infertilidade são diversas, dentre elas destacam-se: ausência de útero por alterações congênitas - como síndrome de Mayer-Rokitansky-Küster-Hauser (MRKH), iatrogenia - histerectomia por câncer cervical, leiomiomatose uterina, hemorragia pós-parto não controlada e problemas anatômicos ou fisiológicos aderências intra-uterinas, adenomiose e malformações uterinas congênitas (BRUNO B e ARORA KS, 2018).

No que tange à maternidade, as mulheres portadoras de IAFU, até recentemente, tinham como opções apenas a adoção e a barriga de aluguel (O'DONOVAN L, et al., 2019; SASO S, 2016). No entanto, essas alternativas estão acompanhadas de fatores limitantes, como processo burocrático e custo elevado, respectivamente (O'DONOVAN L, et al., 2019; SANDMAN L, 2018).

Além disso, alguns países como Japão, Turquia e Suécia apresentam restrições legais quanto à barriga de aluguel. Nesse contexto, o transplante uterino (TU), embora experimental, surge como alternativa terapêutica para essas mulheres que não têm outra opção de engravidar (EJZENBERG D, et al., 2016; KISU I, et a.I, 2016; API M, et al., 2017; McTERNAN E, 2018; O'DONOVAN L, et al., 2019).

O TU e do colo uterino é um aloenxerto de vários tecidos, que, ao contrário de outros transplantes, é compartilhado por duas pessoas, mãe e filho (TESTA G, et al., 2017). Apesar deste não ser um transplante de órgão vital, influencia diretamente na qualidade de vida da mulher que deseja passar pela experiência da gestação (KISU I et al., 2016).

Essa modalidade de tratamento está disponível para mulheres que atendem os seguintes critérios: cariótipo XX, capacidade de fornecer seus próprios ovócitos e embriões, de criar filhos - além de ter razões válidas para a procura do tratamento (O'DONOVAN L, et al., 2019). Sampson A, et al. (2019), expressa em seu estudo a potencialidade de se incluir, futuramente, as mulheres geneticamente $X Y$ no grupo de possíveis receptoras do TU.

Ademais, para Zaami S, et al. (2017) também é importante a avaliação psicológica especializada, boas condições de saúde, probabilidade de tomar imunossupressores e acompanhamento com equipe especializada de maneira responsável. O órgão pode ser proveniente de doadoras vivas ou que tiveram morte cerebral decretada (KISU I, et al., 2018). 
Segundo Kuo CY, et al. (2017), Brännström M, et al. (2019) e Api M, et al. (2017), a primeira experiência de TU intervivos foi realizada na Arábia Saudita, em 2000, mas, devido a complicações vasculares do enxerto, foi necessária a sua remoção após 3 meses. Depois, em 2013, ocorreu na Turquia um TU de doadora não viva que resultou em gravidez clínica, mas evoluiu com abortamento (API et al, 2017). Já na Suécia, no mesmo ano, foi realizada uma coorte com nove mulheres submetidas ao TU com doadoras vivas e, em 2014, ocorreu o primeiro parto bem sucedido com criança saudável desse estudo (BRÄNNSTRÖM M, et al., 2018). Já no Brasil, o primeiro TU foi realizado em 2016, com órgão de doadora não viva. A receptora era uma mulher portadora da síndrome de MRKH (BOCCIO MV, et al., 2019).

O TU perpassa por algumas questões éticas emblemáticas, como o fato de não salvar vidas, ser um procedimento experimental e apresentar altos riscos associados a resultados incertos (ZAAMI S, et al., 2017). Além disso, é discutido a respeito dos critérios para alocação dos órgãos doados, visto que há uma grande demanda para uma pequena oferta (BRUNO B e ARORA KS, 2018). De acordo com McTernan E (2018), a adoção é eticamente preferível, pois leva em consideração o fato de que existem muitas crianças na fila de espera. Por outro lado, para Bruno B e Arora KS (2018), o argumento que melhor defende o transplante de útero é o respeito à autonomia e ao direito das pessoas de tomarem decisões com base em suas crenças.

Diante dessas diversas perspectivas sobre o TU, faz-se necessário um aprofundamento na questão, tanto no que tange às possíveis candidatas ao procedimento, quanto à realização da cirurgia e suas complicações. É um tema bastante atual, o que revela a relevância de ser mais estudado e compreendido. Assim sendo, o estudo em questão tem como objetivo realizar uma revisão sistemática a respeito do TU, como opção terapêutica para mulheres com IAFU que apresentam desejo reprodutivo.

\section{MÉTODOS}

Após a delimitação do tema de escolha foi utilizado o site Descritores em Ciências da Saúde (DeCS), para a seleção dos descritores. A partir disso, foram escolhidos os seguintes: infertility, transplant e uterus - e suas respectivas traduções em português e espanhol.

$\mathrm{Na}$ sequência foram utilizadas três bases de dados para a pesquisa de artigos: Pubmed, Literatura LatinoAmericana e do Caribe em Ciências da Saúde (LILACS) e Coordenação de Aperfeiçoamento de Pessoal de Nível Superior (CAPES). Os termos foram inseridos em formulário avançado, combinados entre si. No Pubmed, os descritores utilizados para a pesquisa, resultaram em 536 artigos. Subsequentemente, foi adicionado o filtro free full text, o filtro para tempo, selecionando artigos com menos de 5 anos e o filtro para espécies humanas, o que reduziu o número de artigos para 51. Desses, foram selecionados 24 que abordavam o tema escolhido.

$\mathrm{Na}$ base de dados LILACS, os descritores pesquisados resultaram em 3 artigos, sendo que foram escolhidos 2 que abordavam a espécie humana. Na terceira base de dados utilizada, o CAPES, foram utilizados os mesmos descritores supracitados, resultando em 777 artigos. Refinou-se a busca com os seguintes filtros: últimos 5 anos, humanos, periódicos revisados por pares, em inglês. Assim, reduziu-se o número de artigos para 322 . Dos 322 artigos, foram excluídos, pela análise título, os que não tratavam do assunto de interesse e/ou os que não se conseguiu acesso ao artigo completo. Por fim, foram selecionados 19 artigos que abordavam acerca da temática.

A pesquisa nas três bases de dados resultou 19 artigos do CAPES, 2 do LILACS e 24 do Pubmed - totalizando assim, 45 artigos pré-selecionados. Em seguida, os artigos foram inicialmente avaliados pelos pesquisadores, quanto ao título e resumo; a fim de determinar o objeto do estudo e se adequavam-se ao tema proposto. Dessa maneira, restaram 13 artigos para seguirem na seleção.

A partir dessa amostra, os pesquisadores continuaram com o processo de seleção, e foram utilizados como fatores de inclusão: (1) o desenho do estudo (ensaio clínico, coorte e estudos transversais); (2) os artigos com metodologia bem delimitada e descrita; (3) Estudo feito com mulheres submetidas ao transplante de útero. E os critérios de exclusão foram: (1) Fuga ao tema proposto; (2) Estudos de Revisão, Meta-análise, Relato de Caso e Guidelines. 
Os 13 trabalhos remanescentes foram analisados na íntegra para a adequação aos critérios de inclusão e exclusão acima citados. Por fim, 5 artigos foram selecionados. Todo o processo de busca, análise e seleção dos estudos pode ser visualizado na Figura 1.

Figura 1 - Processos de seleção dos artigos.

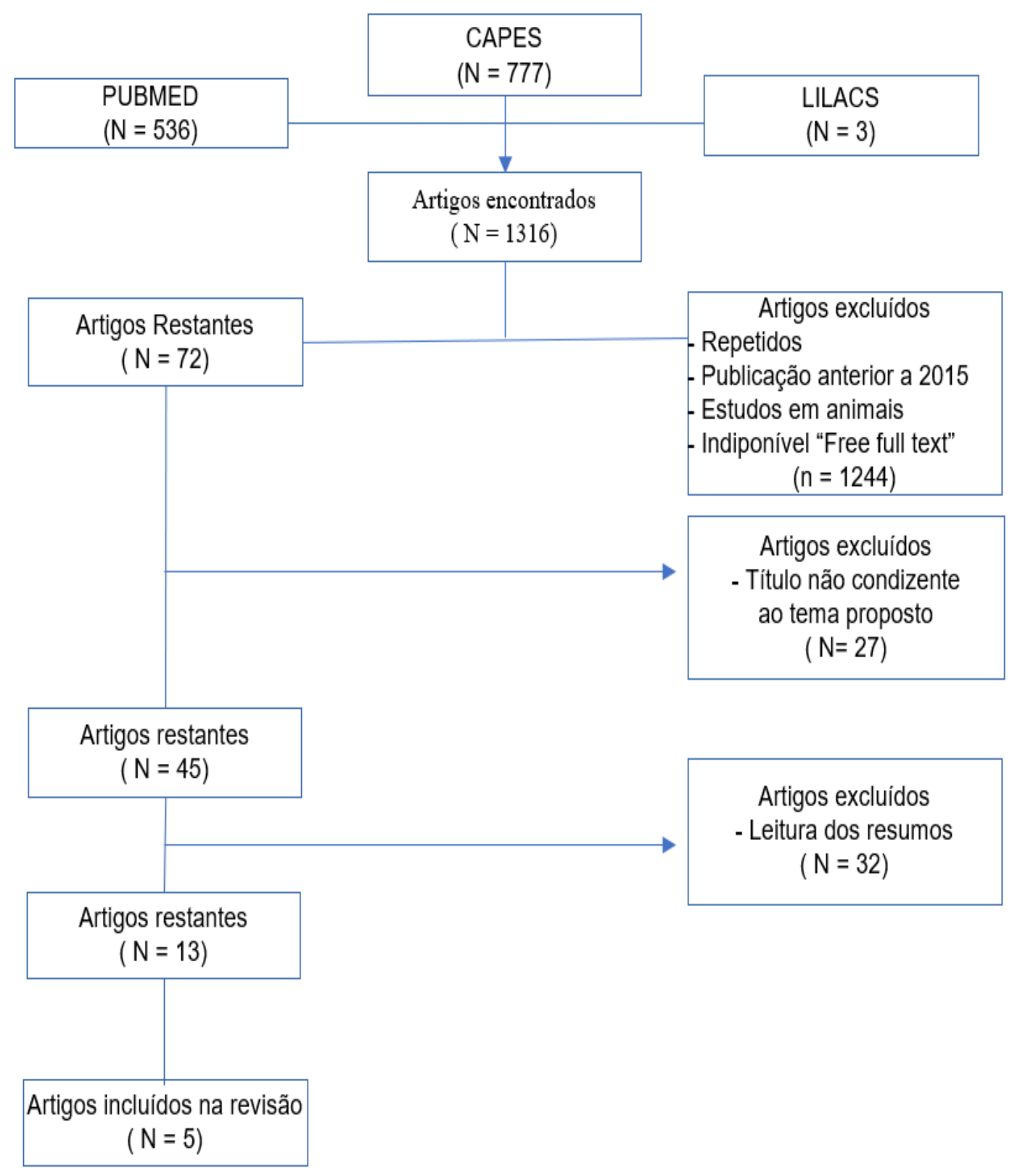

Fonte: Campos CA, et al., 2020.

\section{RESULTADO E DISCUSSÃO}

A partir da análise dos artigos selecionados na metodologia, foi possível revisar um total de 5 ensaios clínicos que abordaram o uso do transplante uterino para o tratamento da IAFU. Os aspectos particulares de cada estudo tais como, autoria, amostra estudada, análise de doadores e receptores e os principais desfechos estão expostos nas tabelas abaixo (Quadro 1, Quadro 2, Quadro 3). 
Quadro 1 - Dados Gerais.

\begin{tabular}{|c|c|c|c|c|}
\hline Autores & País & População & Número (N) & $\begin{array}{c}\text { Principal critério observado no } \\
\text { estudo }\end{array}$ \\
\hline $\begin{array}{l}\text { Mahmood S, } \\
\text { et al. (2019) }\end{array}$ & $\begin{array}{l}\text { Dallas, TX, } \\
\quad \text { USA }\end{array}$ & $\begin{array}{c}\text { Mulheres submetidas } \\
\text { ao transplante de } \\
\text { útero }\end{array}$ & 11 & $\begin{array}{l}\text { Qualidade dos vasos uterinos da } \\
\text { doadora no sucesso do transplante }\end{array}$ \\
\hline $\begin{array}{l}\text { Testa G, et } \\
\text { al. (2017) }\end{array}$ & $\begin{array}{l}\text { Gotemburgo, } \\
\text { Suécia }\end{array}$ & $\begin{array}{c}\text { Mulheres submetidas } \\
\text { ao transplante de } \\
\text { útero }\end{array}$ & 5 & $\begin{array}{c}\text { Patologia vascular uterina relacionada } \\
\text { à idade da doadora }\end{array}$ \\
\hline $\begin{array}{l}\text { Chmel R, et } \\
\text { al. (2018) }\end{array}$ & $\begin{array}{l}\text { República } \\
\text { Tcheca }\end{array}$ & $\begin{array}{c}\text { Mulheres submetidas } \\
\text { ao transplante de } \\
\text { útero }\end{array}$ & 9 & $\begin{array}{l}\text { A diferença entre doadoras vivas ou } \\
\text { falecidas }\end{array}$ \\
\hline $\begin{array}{l}\text { Taran FA, et } \\
\text { al. (2019) }\end{array}$ & $\begin{array}{l}\text { Tübingen, } \\
\text { Alemanha }\end{array}$ & $\begin{array}{c}\text { Possíveis receptoras } \\
\text { do transplante } \\
\text { uterino }\end{array}$ & 15 & $\begin{array}{l}\text { Triagem e seleção de possíveis } \\
\text { doadoras e receptoras }\end{array}$ \\
\hline $\begin{array}{c}\text { Johannesso } \\
\mathrm{n} \mathrm{L} \text {, et al. } \\
\text { (2015) }\end{array}$ & $\begin{array}{l}\text { Gotemburgo, } \\
\text { Suécia }\end{array}$ & $\begin{array}{c}\text { Mulheres submetidas } \\
\text { ao transplante de } \\
\text { útero }\end{array}$ & 9 & $\begin{array}{l}\text { Análise da imunossupressão, } \\
\text { menstruação e ultrassom uterino, após } \\
\text { transplante }\end{array}$ \\
\hline
\end{tabular}

Fonte: Campos CA, et al. 2020.

Quadro 2 - Análise de doadores e receptores.

\begin{tabular}{|c|c|c|c|c|}
\hline Autores & Tipo de doador & Não vivo & Critério de infertilidade & Idade \\
\hline $\begin{array}{c}\text { Mahmood S, } \\
\text { et al. (2019) }\end{array}$ & 9 doadoras vivas & Não houve & $\begin{array}{r}\text { Fatores congênitos, funcionais ou } \\
\text { adquiridos }\end{array}$ & Não mencionado \\
\hline $\begin{array}{c}\text { Testa G, et } \\
\text { al. (2017) }\end{array}$ & 5 doadoras vivas & Não houve & $\begin{array}{c}\text { Ausência definitiva ou mal } \\
\text { formação do útero, disfunção } \\
\text { aduirida do útero ou perda uterina } \\
\text { por patologias benignas, ou } \\
\text { malignas, ou por complicações pós } \\
\text { parto }\end{array}$ & $\begin{array}{c}\text { Doadores: } 40-65 \text { anos. } \\
\text { Receptoras de 20-35 } \\
\text { anos. }\end{array}$ \\
\hline $\begin{array}{c}\text { Chmel R, et } \\
\text { al. (2018) }\end{array}$ & 5 doadoras vivas & 4 doadoras & $\begin{array}{c}\text { Mulheres com síndrome congênita } \\
\text { ou adquirida, levando a uma } \\
\text { ausência uterina ou a um útero não } \\
\text { funcional }\end{array}$ & $\begin{array}{c}\text { Doadoras: 20-58 anos } \\
\text { Receptoras: 23-33 }\end{array}$ \\
\hline $\begin{array}{c}\text { Taran FA, et } \\
\text { al. (2019) }\end{array}$ & 16 doadoras vivas & Não houve & $\begin{array}{c}\text { Não funcionalidade ou ausência } \\
\text { uterina por aplasia congênita ou } \\
\text { histerectomia. }\end{array}$ & $\begin{array}{c}\text { Doadoras: } 37-62 \text { anos } \\
\text { Receptoras: 22-35 } \\
\text { anos }\end{array}$ \\
\hline $\begin{array}{c}\text { Johannesso } \\
\text { n L, et al. } \\
\text { (2015) }\end{array}$ & 9 doadoras vivas & Não houve & Não relata & $\begin{array}{c}\text { Receptoras: 27-35 } \\
\text { anos }\end{array}$ \\
\hline
\end{tabular}

Fonte: Campos CA, et al. 2020. 
Quadro 3 - Resultados após Transplante Uterino.

\begin{tabular}{|c|c|c|c|c|c|c|}
\hline \multirow[b]{2}{*}{ Autores } & \multirow[b]{2}{*}{$\begin{array}{c}\mathrm{N} N \text { de } \\
\text { transplantes } \\
\text { realizados }\end{array}$} & \multicolumn{2}{|c|}{ Resultados positivos } & \multicolumn{3}{|c|}{ Resultados negativos } \\
\hline & & $\begin{array}{c}\text { Utero viável } \\
\text { com } \\
\text { menstruação }\end{array}$ & $\begin{array}{l}\text { Gestação com } \\
\text { filho vivo }\end{array}$ & Histerectomia & $\begin{array}{c}\text { Trombose } \\
\text { da a. } \\
\text { uterina }\end{array}$ & $\begin{array}{c}\text { Outras } \\
\text { intercorrências } \\
\text { citadas }\end{array}$ \\
\hline $\begin{array}{l}\text { Mahmood } \\
\text { S, et al. } \\
\text { (2019) }\end{array}$ & 11 & $4(36 \%)$ & $2(18 \%)$ & $5(45 \%)$ & $1(9 \%)$ & $\begin{array}{c}1(9 \%) \text { Sangramento } \\
\text { Uterino } \\
3(27 \%) \text { necrose } \\
\text { uterina } \\
1(9 \%) \text { aborto }\end{array}$ \\
\hline $\begin{array}{l}\text { Testa G, } \\
\text { et al. } \\
(2017)\end{array}$ & 5 & $2(40 \%)$ & $\begin{array}{c}\text { Tempo } \\
\text { insuficiente } \\
\text { de } \\
\text { acompanhamento }\end{array}$ & $3(60 \%)$ & $2(40 \%)$ & $\begin{array}{c}1(20 \%) \text { Necrose } \\
\text { uterina }\end{array}$ \\
\hline $\begin{array}{l}\text { Chmel R, } \\
\text { et al. } \\
(2018)\end{array}$ & 9 & $6(67 \%)$ & 0 & $3(33 \%)$ & $2(22 \%)$ & $\begin{array}{c}1(11 \%) \text { Fístula } \\
\text { vesicovaginal } \\
2(22 \%) \text { ITUs } \\
1(11 \%) \text { Histerectomia } \\
\text { por HPV } \\
9 \text { Casos de rejeição } \\
\text { tratável }\end{array}$ \\
\hline $\begin{array}{l}\text { Johannes } \\
\text { son } L, \text { et } \\
\text { al. }(2015)\end{array}$ & 9 & $7(78 \%)$ & $\begin{array}{c}\text { Tempo } \\
\text { insuficiente de } \\
\text { acompanhamento }\end{array}$ & $2(22 \%)$ & $1(11 \%)$ & $\begin{array}{c}1(11 \%) \text { Infecção } \\
\text { intrauterina resistente } \\
5 \text { Casos de rejeição } \\
\text { tratável }\end{array}$ \\
\hline
\end{tabular}

Fonte: CAMPOS CA, et al. 2020.

\section{Critério de abordagem dos estudos}

Os estudos abordam critérios distintos para elucidar processos envolvidos na realização do transplante uterino. No artigo de Mahmood S, et al. (2019), e de Testa G, et al. (2017), o foco principal foi a avaliação da qualidade dos vasos sanguíneos uterinos das doadoras, sendo que o primeiro prioriza o impacto do uso de exames de imagem, e o segundo relaciona a patologia vascular à idade da doadora. Ademais, o artigo de Johannesson L, et al. (2015) também utiliza a imagem, no caso a ultrassonografia (USG) uterina, como método de análise, além da imunossupressão e da menstruação como parâmetros estudados.

Em contrapartida, a comparação entre as doadoras vivas e não-vivas é o tópico de maior relevância para o estudo de Chmel R, et al. (2018) e a triagem e seleção de possíveis doadoras e receptoras é o foco de Taran FA, et al. (2019). Percebe-se que não há ainda um padrão técnico a se seguir nos estudos para o bom prognóstico do transplante. Diante disso, os diferentes critérios abordados demonstram a atualidade do tema e que pesquisas ainda estão sendo realizadas para alcançar o sucesso do TU.

Outro ponto relevante da revisão foi a consistência dos métodos e o rigor na condução do estudo. No artigo de Mahmood S, et al. (2019), a idade das doadoras e receptoras não foi especificada, o que constitui um possível viés metodológico, uma vez que a idade da amostra é um fator determinante no sucesso desse tipo de transplante. No que tange o valor da quantidade amostral, o estudo de Testa G, et al. (2017) analisa apenas cinco mulheres submetidas ao TU, o que pode configurar em uma baixa precisão dos resultados.

Outro fator que pode prejudicar a credibilidade do estudo é o tempo insuficiente de acompanhamento após o TU nos estudos de Johannesson L, et al. (2015) e Testa G, et al. (2017). Essa redução na avaliação longitudinal da amostra pode reduzir as taxas de identificação de complicações a longo prazo. Diante disso, é importante reconhecer as falhas de metodologia presentes nos estudos a fim de fazer uma melhor análise dos resultados e compreender as vantagens e as desvantagens desse transplante. 


\section{Análise de doadores e receptores}

Os critérios de inclusão e exclusão das doadoras variam conforme o objetivo de cada ensaio clínico, considerando que não há um consenso entre os pesquisadores a respeito da melhor forma de seleção dessa amostra. Embora a maioria dos estudos considerem a idade como um fator de exclusão em comum, eles também possuem divergências em relação a estes. No estudo de Mahmood S, et al. (2019), o principal critério utilizado envolve a qualidade dos vasos arteriais e venosos observados na ultrassonografia pélvica com Doppler. Ademais, a triagem é complementada com uso de angiotomografia e angioressonância magnética.

Além dos exames utilizados por Mahmood S, et al. (2019), Testa G, et al. (2017), em seu estudo, também utiliza a ecografia vaginal e considera as sorologias negativas para infecções sexualmente transmissíveis como um relevante critério de exclusão para a pesquisa. Por esse motivo, este foi o único artigo selecionado, por considerar os resultados de sorologias das doadoras e das receptoras como um ponto a ser analisado, o que é relevante por tratar-se de um transplante que envolve o útero, órgão possivelmente afetado por doenças sexualmente transmissíveis.

Chmel R, et al. (2018) é o único que aborda doadores não vivos e faz um estudo retrospectivo de seus históricos de saúde; levando em conta comorbidades, como hipertensão arterial, diabetes mellitus e câncer, e anormalidades uterinas. Taran FA, et al. (2019) também considera o histórico de intercorrências como fator relevante para exclusão de doadoras. Contudo, seus fatores de inclusão envolvem questões legais relacionadas à Lei Alemã de Transplantes, que discorre acerca da aquisição de órgãos de pessoas falecidas e vivas. Essa lei determina que o doador desse órgão não vital seja parente vivo, cônjuge, parceiro póstumo ou indivíduo comprovadamente próximo do receptor.

Um ponto importante observado nos estudos é a escolha criteriosa da amostragem dos receptores. A maioria dos artigos descreve de forma semelhante que as possíveis receptoras deverão estar em idade reprodutiva e apresentarem fatores de infertilidade uterina. Contudo, existem divergências entre os demais fatores de escolha. No estudo do Testa G, et al. (2017), foram selecionadas mulheres sem nenhuma cirurgia prévia, com contagem folicular de 8 a 19 e que possuem de 7 a 8 embriões congelados.

Já no artigo de Taran FA, et al. (2019), um dos pontos chaves do estudo de foi a exclusão de potenciais receptoras com cariótipos femininos anormais, e, importante ressaltar, que todos os critérios de inclusão e exclusão basearam se exclusivamente em avaliação médica e na experiência da equipe. Por fim, Chmel $R$, et al. (2018) utiliza receptoras que foram minuciosamente examinadas antes do TU, abordando questões relativas à qualidade da vida sexual e um processo de triagem de 4 estágios, que abordava os riscos e os benefícios do novo tratamento experimental.

Em suma, observa-se que os estudos são empíricos e que não há um protocolo pré estabelecido para a triagem amostral dos doadores e dos receptores e, nesse contexto, cada estudo abordou uma faceta do processo de TU, o qual envolve diversos aspectos físicos e até mesmo sociais. Dessa forma, justifica-se a dificuldade de abordagem similar dos doadores e receptores nos estudos selecionados para a análise.

\section{Técnica Cirúrgica}

Os artigos não apresentam como um de seus objetivos a descrição e detalhamento da técnica cirúrgica utilizada no transplante uterino. Assim como já descrito anteriormente, por ser ainda um procedimento experimental, não há protocolo específico nesse âmbito. Entre os estudos analisados, o estudo de Chmel R, et al. (2018) é o único que abrange a técnica cirúrgica tanto em doadores quanto em receptores.

Chmel R, et al. (2018) descreve que, para aquisição do órgão da doadora, é realizada uma laparotomia com a dissecção do útero e das artérias e veias uterinas bilaterais, incluindo os vasos ilíacos internos. Todas as doadoras submetidas a essa cirurgia tiveram as veias ovarianas dissecadas juntamente com o útero e com os vasos uterinos. Após a retirada e lavagem do enxerto, inicia-se a cirurgia da receptora com uma incisão infra umbilical na linha média. Os vasos ilíacos externos bilaterais são dissecados e separados um do outro. 
Ainda na cirurgia de Chmel R, et al. (2018), o útero é posicionado no interior da pelve e são realizadas as anastomoses vasculares de ponta a ponta dos vasos ilíacos externos. Após a confirmação da reperfusão, é feita uma abertura vaginal de acordo com o tamanho do colo uterino, e a borda vaginal do órgão transplantado é anastomosada na vagina da receptora usando suturas simples interrompidas com fios reabsorvíveis. Por fim, o útero é fixado em sua localização pélvica usando os ligamentos redondo e uterosacral, além do peritônio da bexiga adjacente do doador.

Para Testa G, et al. (2017), a cirurgia de retirada do útero é mais complexa que uma simples histerectomia e, portanto, esse é o foco da técnica cirúrgica abordada no estudo uma vez que é necessária a dissecção total do pedículo vascular. Nesse ensaio clínico, a anastomose arterial é feita com a artéria ilíaca interna do doador e a artéria ilíaca externa do receptor. Além disso, a anastomose venosa foi realizada com a veia uterina ou úteroovariana, a depender da melhor saída venosa do útero. Depois da reperfusão, o colo uterino é anastomosado na receptora.

Assim como Testa G, et al. (2017), Johannesson L, et al. (2015) reforça a importância de se preservar os pedículos vasculares para a anastomose das artérias ilíacas internas do doador com as artérias ilíacas externas do receptor. Em contrapartida, Mahmood S, et al. (2019) utiliza as artérias uterinas do doador para anastomose bilateral com as artérias ilíacas externas do receptor. Apesar de não haver um protocolo específico relacionado às técnicas cirúrgicas a serem realizadas, é notório um certo consenso em relação a importância da preservação do pedículo vascular e da realização das anastomoses das artérias ilíacas.

\section{Resultados após transplante}

A partir da análise dos artigos selecionados, foram considerados como resultados positivos a presença de úteros viáveis com menstruação e/ou de gestação com filho vivo, no entanto, metade desses estudos tiveram tempo insuficiente de acompanhamento para o segundo desfecho. O estudo de Mahmood S, et al. (2019), por exemplo, apresentou 54\% das receptoras com útero viável com menstruação e foi o único estudo que apresentou gestação com filho vivo, em 18\% das pacientes. Tanto o Chmel R, et al. (2018) quanto o Johannesson L, et al. (2015) apresentaram grande porcentagem de úteros viáveis com menstruação, 67\% e 78\%, respectivamente.

Nenhum dos estudos supracitados, exceto o de Mahmood S, et al. (2019), apresentou gestação com filho vivo, sendo no caso de Johannesson L, et al. (2015) em detrimento do tempo insuficiente de acompanhamento. Em contrapartida, o estudo de Testa G, et al. (2017), além de apresentar uma pequena amostra de transplantes realizados, apenas $40 \%$ das receptoras tiveram útero viável com menstruação. Somado a isso, o tempo de acompanhamento foi insuficiente para a ocorrência de gestação.

Os desfechos negativos apresentados nos artigos englobam histerectomia e outras demais intercorrências. No estudo de Mahmood S, et al. (2019), foi realizada a retirada cirúrgica do útero em $45 \%$ das mulheres, sendo que em $9 \%$ foi em decorrência de trombose da artéria uterina, 9\% devido à sangramento uterino extenso e $27 \%$ em razão de necrose uterina. Neste mesmo ensaio clínico, houve 1 aborto espontâneo com a manutenção da viabilidade uterina. Já no estudo de Testa G, et al. (2017) os desfechos negativos são significativos, apresentando uma taxa de $60 \%$ de histerectomia, sendo $40 \%$ por trombose da artéria uterina e $20 \%$ por necrose uterina.

No artigo de Chmel R, et al. (2018), ocorreu uma taxa de 33\% de retirada cirúrgica do útero, sendo 22\% devido a trombose da artéria uterina e $11 \%$ devido a infecção pelo papilomavírus humano (HPV). Nesse mesmo estudo, houve outras intercorrências passíveis de tratamento, como fístula vesicovaginal em $11 \%$ dos casos, Infecção do trato urinário (ITU) em $22 \%$ e 9 casos de rejeição uterina.

Enfim, o último artigo que abordou os resultados negativos no estudo foi o de Johannesson L, et al. (2015), em que houve uma taxa de $22 \%$ de histerectomia; sendo $11 \%$ devido a trombose da artéria uterina e $11 \%$ devido a uma infecção intrauterina resistente a antibióticos. Nesse mesmo ensaio ocorreram 5 casos de rejeição uterina tratável.

REAS/EJCH | Vol.12(10) | e4626 | DOI: https://doi.org/10.25248/reas.e4626.2020

Página 8 de 9 


\section{CONSIDERAÇÕES FINAIS}

O TU é um processo complexo e seus riscos e benefícios precisam ser cuidadosamente avaliados. Ademais, esse é um procedimento recente e, por isso, necessita de mais estudos e avanços para que essa modalidade terapêutica seja estabelecida como uma opção segura e disponível para as mulheres com IAFU. Apesar do alto custo do transplante e de muitos autores não considerarem a infertilidade causada por disfunção uterina como uma patologia, a Organização Mundial de Saúde (OMS) considera que saúde é "um estado de completo bemestar físico, mental e social e não somente ausência de afecções e enfermidades". Portanto, é necessário reconhecer o quão relevante pode ser a vivência de uma gestação na saúde de uma mulher.

\section{REFERÊNCIAS}

1. API M, BOZA A, CEYHAN M. Could the female-to-male transgender population be donor candidates for uterus transplantation? Turkish journal of obstetrics and gynecology.2017; 14(4), 233-237.

2. BOCCIO MV, et al. Uterine transplant: current results. Preparation of a multidisciplinary team in argentina.Rev. med. Rosario. 2019; 85(2): 81-87.

3. BRÄNNSTRÖM M. Introduction: Uterus transplantation. Fertil Steril. 2019;112(1):1-2.

4. BRUNO B, ARORA KS. Uterus Transplantation: The Ethics of Using Deceased Versus Living Donors. Am J Bioeth. 2018;18(7):6-15.

5. CHMEL R, et al. Revaluation and lessons learned from the first 9 cases of a Czech uterus transplantation trial: Four deceased donor and 5 living donor uterus transplantations. Am J Transplant. 2019;19(3):855-864.

6. EJZENBERG D, et al. Uterine transplantation: a systematic review. Clinics.2016; 71(11), 679-683.

7. EJZENBERG D, SOARES JMJ, BARACAT EC. Uterus transplant: Are we close to this reality? Rev Assoc Med Bras (1992). 2016;62(4):295-296.

8. JOHANNESSON L, et al. Uterus transplantation trial: 1-year outcome. Fertil Steril. 2015;103(1):199-204.

9. JONES BP. The vaginal microbiome in uterine transplantation. BJOG. 2020;127(2):230-238.

10. KISU I, et al. Emerging problems in uterus transplantation. BJOG. 2018;125(11):1352-1356.

11. KISU I, et al. Survey of Attitudes toward Uterus Transplantation among Japanese Women of Reproductive Age: A CrossSectional Study. PLoS One. 2016;11(5): e0156179.

12. KUO CY, et al. Bioengineering Strategies to Treat Female Infertility. Tissue Eng Part B Rev. 2017;23(3):294-306.

13. MAHMOOD S, et al. DUETS (Dallas UtErus Transplant Study): The role of imaging in uterus transplantation. SAGE Open Med. 2019 Sep 9; 7:2050312119875607.

14. MCTERNAN E. Uterus transplants and the insufficient value of gestation. Bioethics. 2018;32(8):481-488.

15. O'DONOVAN L, WILLIAMS NJ, WILKINSON S. Ethical and policy issues raised by uterus transplants. British Medical Bulletin. 2019;131(1):19-28.

16. SAMPSON A, et al. Uterus transplantation in women who are genetically XY. Journal of Medical Ethics. 2019; 45:687-689.

17. SANDMAN L. The importance of being pregnant: On the healthcare need for uterus transplantation. Bioethics. 2018;32(8):519-526.

18. SASO S, et al. Psychological Issues Associated with Absolute Uterine Factor Infertility and Attitudes of Patients Toward Uterine Transplantation. Prog Transplant. 2016;26(1):28-39.

19. TARAN FA, et al. Screening and evaluation of potential recipients and donors for living donor uterus transplantation: results from a single-center observational study. Fertil Steril. 2019;111(1):186-193.

20. TESTA G, et al. Living Donor Uterus Transplantation: A Single Center's Observations and Lessons Learned from Early Setbacks to Technical Success. Am J Transplant. 2017;17(11):2901-2910.

21. ZAAMI S, et al. Ethical and medico-legal remarks on uterus transplantation: may it solve uterine factor infertility? Eur Rev Med Pharmacol Sci. 2017;21(22):5290-5296. 